\title{
The Influence of Parents' Anxiety on Children's Anxiety: Mediation Effects of Parents' Overprotection and Children's Cognitive Distortions
}

\author{
Youngmi Kim ${ }^{1}$, Hana Song ${ }^{2}$ \\ Instructor, Department of Child Psychology and Education, Sungkyunkwan University, Seoul, Korea ${ }^{1}$ \\ Professor, Department of Child Psychology and Education, Sungkyunkwan University, Seoul, Korea ${ }^{2}$ \\ 부모의 불안이 아동의 불안에 미치는 영향: 과보호 양육과 아동의 \\ 인지적 왜곡의 매개효과 검증 \\ 김영미 ${ }^{1}$, 송하나 ${ }^{2}$ \\ 성균관대학교 아동·청소년학과 겸임교수 ${ }^{1}$, 성균관대학교 아동·청소년학과 교수 ${ }^{2}$
}

Objectives: This study examined the relationship between parents' and children's anxiety and the mediation effects of parents' overprotection and children's cognitive distortions.

Methods: The participants were 414 children in fourth, fifth, and sixth grade in elementary schools and their parents. Structural equation modeling was used to analyze the data.

Results: First, children's cognitive distortions and parents' overprotection were found to directly affect the children's anxiety. Parents' overprotection also affected the children's anxiety and was mediated by cognitive distortions. However, only the mother's anxiety significantly predicted a child's anxiety.

Conclusion: Findings suggest that there is an intergenerational transmission of anxiety, and early intervention and prevention approaches may be helpful.

Keywords: anxiety, overprotection, cognitive distortion, bias, anxiety control beliefs

\section{Introduction}

최근 보도자료(Yoo, 2018)에 따르면 국내 초·중·고등학생 4,057 명을 대상으로 실시한 정신질환실태조사에서 불안 장애 를 포함한 정신병리 고위험군 유병률이 $36 \%$ 였다. 아동기 불 안은 위험에 대한 적응적 반응으로 볼 수 있는 보편적이고 정 상적인 현상이다(Gullone, 2000). 후기 아동기에는 학업 부담, 또래 관계, 진학 등에서 오는 두려움으로 불안이 크게 증가한 다. 이 때 경험한 불안이 오래 지속되거나 대처가 적절하지 못 할 경우에는 사회·정서적 발달 문제와 병리적 불안 문제가 야 기될 수 있다(Albano, Chorpita, \& Barlow, 2003).

Corresponding Author: Youngmi Kim, Instructor, Department of Child Psychology and Education, Sungkyunkwan University, 25-2, Sungkyunkwan-ro, Jongno-gu, Seoul, Korea

E-mail: nada03001@skku.edu
아동의 불안은 부모의 불안에 의해 영향을 받는다. 불안의 가족력에 대해 다룬 선행 연구에서는 불안한 부모의 자녀가 그렇지 않은 자녀에 비해 불안장애로 진단될 확률이 7배나 높 았으며(Beidel \& Turner, 1997; Biederman et al., 2007), 이란성 쌍생아보다 일란성 쌍생아가 불안장애로 진단될 확률이 약 $30-40 \%$ 높다고 보고되었다(Hettema, Neale, \& Kendler, 2001). 부모의 불안은 직접 경험, 관찰학습, 양육행동 등 사회적 경로 를 통해 아동의 불안에 영향을 준다. 이 중 양육 행동은 불안의 세대 간 전이를 설명해주는 주요한 요인으로 꼽히고 있다.

불안한 어머니와 자녀 간의 상호작용을 관찰한 연구들에 따르면, 불안한 어머니는 그렇지 않은 어머니보다 자녀에게

(C)The Korean Association of Child Studies

This is an Open Access article distributed under the terms of the Creative Commons Attribution Non-Commercial License (http:// creativecommons.org/licenses/by-nc/4.0) which permits unrestricted noncommercial use, distribution, and reproduction in any medium, provided the original work is properly cited. 
덜 애정적인 반면, 자율성을 더 많이 제약하는 것으로 나타났 다(Whaley, Pinto, \& Sigman, 1999; Woodruff-Borden, Morrow, Bourland, \& Cambron, 2002). 이와 같은 자율성의 제약은 과보 호적인 양육 행동으로 나타나게 된다. 과보호 양육행동은 부 모-자녀간의 불안을 가장 잘 설명해주는 양육방식으로 알려 져 있는데 부모가 자녀의 행동을 필요 이상으로 통제하거나 불필요한 도움을 주어 잠재적 위험으로부터 과다하게 보호하 는 것을 의미한다(Hudson \& Rapee, 2001; Vreeke, Muris, Mayer, Huijding, \& Rapee, 2013).

그러나 과보호는 애정과 통제가 모두 포함된 양육 행동으 로 볼 수 있으며 문화권에 따라서도 다르게 해석되는 편이다. 예를 들어, 서구문화권에서의 과보호는 통제나 간섭의 의미가 강조되는 데에 비해 우리나라에서는 지나친 애정이나 돌봄이 라고 해석되기도 한다(Chun, 2012). 문화에 관계없이 높은 수 준의 과보호는 아동이 자신의 환경을 마음껏 탐색할 기회를 박탈하고, 또한 예상치 못한 위협이나 역경에 대처하는 기술 을 터득하지 못하게 한다. 더 나아가 위험에 대한 지각적 민감 성을 높여 아동 스스로 위협적인 상황을 통제할 수 없다고 믿 거나 자신이 처한 상황을 실제보다 더 위협적이라고 해석하게 한다(Barlow, 2001; Chorpita \& Barlow, 1998; Hudson \& Rapee, 2001; Rapee, 1997).

부모의 과보호와 불안과의 관계를 다룬 선행연구들에서는 아버지와 어머니간의 차이가 눈에 띄게 나타난다. 아버지는 어머니보다 자녀들이 독립적이고 모험적인 일을 하도록 격려 하고 자율성을 주는 반면, 어머니는 자녀의 정서적 안정과 신 변 안전을 강조하는 것으로 나타났다(Bogels \& Phares, 2008; Paquette, 2004). Pereira, Barros, Mendonça와 Muris (2014)의 연 구에서 어머니의 경우 특성 불안이 아동에게 영향을 미친 반 면, 아버지는 과보호와 걱정이 자녀 불안에 영향을 미치는 것 으로 나타났다. 국내 연구에서는 아버지보다 어머니가 과잉 간섭하는 경우가 많았으며, 어머니의 과보호가 아동의 불안과 관계가 높은 것으로 나타났다(Suh, Sin, \& Moon, 2010). Suk과 $\mathrm{Oh}$ (2014)의 연구에서는 아버지와 어머니의 과보호적 양육태 도 모두 자녀의 부정적 정서에 부적 영향을 미쳤으나 부모 성 별에 따른 차이는 나타나지 않았다.

이러한 현상은 아버지보다 어머니가 주양육자로서 자녀와 함께 하는 시간이 많고, 자녀의 또래 관계나 학교생활을 더 잘 알아 정서적으로 가깝기 때문에 간섭도 많이 하기 때문인 것 으로 생각된다. 사회에서 통용되는 '미니밴 맘(minivan mom)', '헬리콥터 맘(helicopter mom)', '몬스터 맘(monster mom)', '사 커 맘(soccer mom)' 등 신조어를 통해서도 자녀에 대한 어머니
의 지나친 관심을 엿볼 수 있다. 그러나 최근 주로 양육보조자 의 역할만을 수행하던 아버지의 양육 참여가 눈에 띄게 늘어 아버지의 영향력을 새롭게 살펴볼 필요성이 제기되고 있다. 따라서 본 연구에서는 한국 어머니와 아버지의 과보호가 자녀 에게 어떻게 지각되고 있는지 알아보고 자녀의 불안으로 이어 지는 경로를 확인하고자 하였다.

이와 더불어 불안을 일으키는 중요한 요인으로 인지적 역 할의 중요성이 제기되어 왔다(Beck, Emery, \& Greenberg, 1985; Eysenck \& Calvo, 1992; Harvey, Watkins, Mansell, \& Shafran, 2004). Kendall (1985)에 따르면, 병리적 불안의 증상은 위험과 취약성에 대한 스키마의 과잉 활성화에서 비롯된다. 과잉 활 성화된 스키마는 위협과 관련된 정보를 처리하는 데에 자원 을 집중하게 하여 다른 부분의 인지 왜곡(cognitive distortions) 을 야기한다. 즉, 자원 부족으로 인한 인지 왜곡이 편향된 인 지처리를 하게하여 부적응적인 행동과 사고로 이어지게 된다 (Muris \& Field, 2008).

불안감을 유지시키는 인지 왜곡에는 몇 가지 특징이 포함된 다. 특히, 해석편향과 불안통제신념은 인지적 왜곡의 대표적인 요인이라고 볼 수 있다. 애매모호한 상황을 위협적이라고 쉽게 해석하는 해석 편향(interpretation bias)에 대해, Muris, Merckelbach와 Damsma (2000)는 불안한 아동이 그렇지 않은 아동에 비해 불분명한 상황을 위협적이라고 해석한다고 하였다. 해석 편향에 의한 인지적 왜곡은 불안한 아동과 청소년에게서 자주 나타나지만 어떠한 경로로 발달되는가에 대한 의문이 남아있 다. 유전적 기질이나 성격 특성들이 해석 편향을 결정 짓는다 고 가정하나(Muris \& Field, 2008; Vasey \& MacLeod, 2001), 불 안한 부모의 인지적 왜곡이 해석편향의 형태로 자녀에게 전달 되기도 한다(Muris, Huijding, Mayer, \& Hameetman, 2008).

불안한 부모는 자신의 인지적 왜곡 때문에 자녀에게 모 호한 자극이나 상황에서 부정적인 피드백을 주어 자녀 역시 편향된 사고를 하게 할 수 있다. Creswell, Schniering과 Rapee (2005)는 7-15세 아동과 어머니를 불안 집단과 통제 집단으로 나누어 모호한 상황 시나리오를 제시하였을 때 불안한 집단의 모자간 편향이 상호 관련된 것을 보고하였다. 이후 종단연구 에서도 어머니의 불안한 인지 처리가 아동의 인지 편향을 예 측한다는 것이 밝혀졌다(Creswell, O'Connor, \& Brewin, 2006; Hadwin, Garner, \& Perez-Olivas, 2006).

해석편향과 더불어 인지적 왜곡의 특성으로 자신의 환경 을 통제할 수 있다고 믿는 불안통제신념(anxiety control beliefs) 을 들 수 있다. Chorpita와 Barlow (1998)는 상황을 적절하게 통 제해보는 초기 경험들이 자신의 환경을 통제할 수 있다는 자 


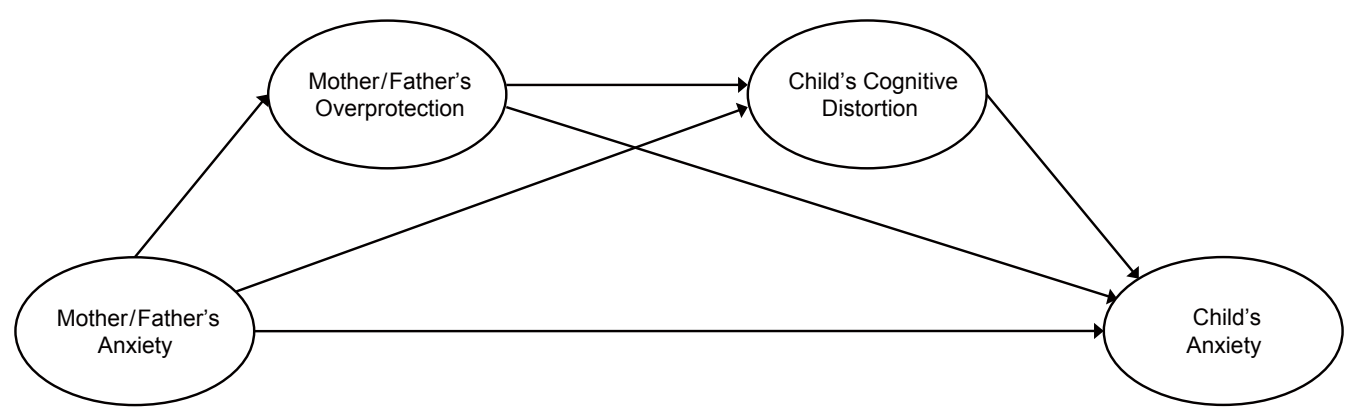

Figure 1. Hypothesized research models.

신감을 갖게 하고 불안을 막는 완충제 역할을 하게 한다고 하 였다. 선행연구들도 지각된 인지적 신념과 불안의 부적인 관 계를 밝혀냈으며(Muris, Schouten, Meesters, \& Gijsbers, 2003; Weems, Silverman, Rapee, \& Pina, 2003), 불안한 아동은 그렇 지 않은 아동에 비해 외적이나 내적 불안과 관련된 사건에 대 한 인지적 통제신념이 낮은 것으로 나타났다(Pereira, Barros, \& Mendoça, 2012a, 2012b).

특히, 불안한 부모의 통제는 부모가 원하는 방식대로 자녀 가 생각하고 느끼고 행동하도록 강요하여 자녀의 자율적 문 제 해결 기회를 빼앗아간다(Hudson \& Rapee, 2004; Van der Bruggen, Stams, \& Bögels, 2008). Becker, Ginsburg, Domingues 과 Tein (2010)은 어머니의 불안과 양육행동이 아동의 불안 에 대한 왜곡적 통제신념으로 이어진다는 것을 확인하였으 며, Chorpita와 Barlow (1998)는 부모의 통제와 아동의 부정적 정서 간의 관계에서 불안통제신념의 매개효과를 밝혀냈다. Gallagher와 Cartwright-Hatton (2008)은 과잉반응적이고 역기 능적인 양육행동이 아동의 인지적 왜곡에 영향을 미쳐 더욱 불안하게 만든다고 하였다. 국내연구들에서는 부모의 과보호 적 양육태도가 자녀의 역기능적 신념과 부정적 자동적 사고를 통하여 불안에 영향을 미치는 것으로 나타났으나 아버지 모형 보다 어머니 모형의 설명력이 높은 것으로 나타났다(Shin \& $\mathrm{Ha}, 2010 ;$ Suk \& Oh, 2014). 그러나 다른 연구(Muris, Meesters, Schouten, \& Hoge, 2004)에서는 부모의 통제와 아동의 불안 간 에 불안통제신념의 매개효과가 나타나지 않았다.

이처럼 위협에 대한 부모의 내재화된 지각이나 통제가 자 녀의 해석편향뿐 아니라 불안통제신념과 같은 인지적 왜곡 의 형성에 상당 부분 기여한다는 것을 입증한 경험적 연구들 이 있으나 결과가 불일치하여 일반화가 어려운 점이 있다. 이 에 본 연구에서는 부모의 과보호를 통해 자녀에게 전달되는 인지적 왜곡의 역할을 살피려 하였다. Barlow (2000)가 주장한 triple-vulnerability model에 따르면 해석 편향과 통제신념은 상 호 영향을 주는 면이 있기 때문에 본 연구에서는 이 두 가지 속
성을 종합한 인지적 왜곡이 전체적으로 부모와 아동 불안 사 이에서 매개역할을 하는지 살펴보고자 하였다.

종합하면, 선행 연구를 통해, 불안한 부모는 자녀가 도전적 이거나 잠재적 위험이 있는 상황 혹은 부정적 정서에 직면하 기 전에 미리 통제를 하거나 과보호를 하고, 이러한 부모의 과 보호적 양육 행동이 인지적 왜곡을 가져올 것으로 가정된다. 구체적으로 본 연구에서는 부모의 과보호적 양육과 아동의 인 지적 왜곡이 아동의 불안과 어떠한 인과적 관련성을 가지고 어떻게 부모 불안에서 아동 불안으로 전이되는 경로를 매개하 는지 두 변인의 매개효과를 아버지와 어머니로 나누어 살펴보 고자 하였다. 본 연구의 연구문제는 다음과 같다.

첫째, 부모의 불안, 과보호 양육과 아동의 인지적 왜곡은 아 동의 불안에 영향을 미치는가?

둘째, 부모의 과보호 양육은 인지적 왜곡을 매개로 아동의 불안에 영향을 미치는가?

셋째, 부모의 불안은 과보호 양육과 인지적 왜곡을 매개로 아동의 불안에 영향을 미치는가?

선행연구의 고찰을 통해 Figure 1 과 같은 가설적 연구모델 을 설정하였다.

\section{Methods}

\section{연구대상}

본 연구는 서울, 경기, 인천, 충청에 소재한 초등학교에 재학 중인 414명의 아동(남아 201명, 여아 213명)과 그들의 부모를 대상으로 하였다. 이 시기의 아동은 불안과 관련된 신체적 증 상에 대한 변화를 인지할 수 있으며 자신의 생각과 정서를 표 현하는 데 인지적으로 성숙하고 안정적이기 때문에 초등학 교 고학년 아동을 대상으로 선정하였다(Harter, 1988; Muris, Vermeet, \& Horselenberg, 2008). 연령별로 4학년 124명, 5학 
년 138 명, 6학년 152 명이었다. 아동의 평균 연령은 12.07 세 $(S D=.82)$, 아버지의 평균 연령은 44.71 세 $(S D=4.15)$, 어머니 의 평균 연령은 42.27 세 $(S D=3.78)$ 이었다. 연구대상의 인구학 적 특성은 Table 1 과 같다.

Table 1

Demographics of Participants

\begin{tabular}{|c|c|c|c|c|}
\hline \multicolumn{3}{|c|}{ Variables } & \multirow{2}{*}{$\begin{array}{c}\text { Frequency }(n) \\
201\end{array}$} & \multirow{2}{*}{$\begin{array}{c}\text { Percent }(\%) \\
48.6\end{array}$} \\
\hline \multirow[t]{10}{*}{ Child } & Gender & Boys & & \\
\hline & & Girls & 213 & 51.4 \\
\hline & Grade & 4th & 124 & 30.0 \\
\hline & & 5 th & 138 & 33.3 \\
\hline & & 6th & 152 & 36.7 \\
\hline & Birth order & First & 148 & 41.1 \\
\hline & & Second & 136 & 37.9 \\
\hline & & Third & 53 & 14.6 \\
\hline & & Fourth or more & 23 & 6.4 \\
\hline & & Missing & 54 & 13.1 \\
\hline \multirow[t]{5}{*}{ Father } & Age & $30-34$ & 2 & .5 \\
\hline & & $35-39$ & 46 & 11.0 \\
\hline & & $40-44$ & 142 & 34.4 \\
\hline & & $45-49$ & 174 & 42.1 \\
\hline & & over 50 & 50 & 12.0 \\
\hline \multirow[t]{5}{*}{ Mother } & Age & $30-34$ & 3 & .8 \\
\hline & & $35-39$ & 93 & 22.4 \\
\hline & & $40-44$ & 198 & 47.9 \\
\hline & & $45-49$ & 104 & 24.9 \\
\hline & & over 50 & 16 & 3.8 \\
\hline
\end{tabular}

\section{연구도구}

\section{부모 변인}

불안 부모 불안을 측정하기 위해 Spielberger (1989)가 개발한 상태-특성 불안척도(State-Trait Anxiety Inventory [STAI])를 사 용하였다. 상태불안은 걱정, 염려, 초조, 긴장 등 현재 느끼고 있는 상태를 의미하며, 특성불안은 일반적인 상태에서 느끼 는 불안을 의미한다. 각 20 문항씩 총 40 문항으로 되어 있으며, 4 점 척도로 평정한다. 상태불안은 10 개의 긍정문항과 10 개의 부정문항으로 구성되어 있으며, 부정문항들은 역채점되었다. 상태불안의 문항 예시는 "나는 불안하다.", "지금 마음이 조마 조마하다.” 등이며, 특성불안의 문항 예시는 "나는 울적하다.”, “나도 다른 사람들처럼 행복했으면 한다." 등이 있다. 총점의
범위는 40-160점이며 점수가 높을수록 불안도가 높다는 것을 의미한다. 본 연구에서 상태불안의 Cronbach's $\alpha$ 는 아버지 .92, 어머니 .93으로, 특성불안은 아버지 .89, 어머니 .88로, 전체 Cronbach's $\alpha$ 아버지 .87 , 어머니 .83으로 나타났다.

과보호적 양육행동 부모의 과보호적 양육행동에 대한 자녀의 지각을 측정하기 위하여 E.-Y. Chung과 Chang (2008)이 개발 하고 타당화한 과보호척도를 사용하였다. 이 척도는 한국 문 화 특성이 반영된 검사로 총 25 문항으로 이루어져 있으며 아 동이 어머니와 아버지에 대하여 총 두 번을 평정한다. 원래는 5 개의 하위요인으로 구성되어 있으나 자율성 저해, 과잉애정 2개 하위요인의 수렴타당도와 신뢰도가 .43 .53으로 낮게 나 타나 본 연구에서는 제외하고 총 3 개의 하위요인만 분석에 사 용하였다. 과잉기대는 자녀에 대한 지나친 기대와 교육열(예: “내 성적이 부모님의 기대에 못 미치면 실망하신다.”)을, 과잉 통제는 부모가 자녀의 하루 일과나 행동을 통제하고 관리하 는 것(예: “내가 무엇을 하든지 부모님의 허락을 받기를 원하 신다.”)을 의미한다. 과잉보호 및 불안은 자녀를 어린 아이 취 급하며 지나치게 보호하는 것(예: "부모님은 내가 다 컸는데도 나를 아기 취급하신다.”)을 말한다. 4점 척도로 응답하며, 점 수가 높을수록 과보호 성향이 높은 것을 의미한다. 본 연구에 서 과잉기대의 Cronbach's $\alpha$ 는 아버지 .74, 어머니 .75로, 과잉 통제는 아버지 .66, 어머니 .67로, 과잉보호 및 불안은 아버지 .67 , 어머니 .68 로 나타났다.

\section{아동 변인}

불안 아동 불안은 Spielberger (1973)의 State-Trait Anxiety Inventory for Children (STAI-C)를 Choi와 Cho (1990)가 번안하 여 초등학생을 대상으로 표준화한 소아상태불안척도를 사용 하였다. 본 척도는 상태불안 20 문항, 특성불안 20 문항으로 구 성되어 있는 자기보고식 평정척도이다. 상태불안의 문항 예 시는 “나는 지금 마음이 차분하다.", "지금 나는 초조하다.” 등 이며, 특성불안의 문항 예시는 "나는 실수하지 않을까 걱정 한다.”, “쓸데없는 생각이 나를 괴롭힌다.” 등이 있다. 각 항목 에 대하여 3점 리커트 척도로 되어 있으며, 총점의 범위는 40120 점이며 점수가 높을수록 불안도가 높다는 것을 의미한다. 본 연구에서 Cronbach's $\alpha$ 는 상태불안 .89 , 특성불안 .88 , 전체 Cronbach's $\alpha$ 는 .83으로 나타났다.

인지적 왜곡 해석편향 해석편향은 Wilson과 Rapee (2005)가 개 
발한 부정적인 사회적 사건의 파국적 해석 척도(Consequences of Negative Social Events Questionnaire [CONSE-Q])를 수정하여 사용하였다. 16 개의 부정적인 사회적 상황을 제시한 뒤, 각 상 황별 3가지 파국적 해석(타인에 의한 부정적인 평가, 부정적 인 자기평가, 부정적인 장기적 결과)에 대하여 믿는 정도를 9 점 리커트 척도(0-8점)로 평정하도록 되어있다. 예시로 “친구 들 앞에서 발표를 하는 동안 집중하는 것이 어렵다. 만약 이 일 이 발생했다면, 라고 믿을 것이다.”라는 문항에 대해 “반 친 구들은 나를 멍청한 사람이라고 생각한다(부정적인 자기평 가).", "나는 멍청한 사람이다(부정적인 자기평가).", “앞으로 나는 좋은 성적을 절대로 얻지 못할 것이다(부정적인 장기적 결과)."의 세 가지 해석 상황을 제시하였다. 이와 같은 형식으 로 총 48문항으로 이루어졌으며 총점의 범위는 0-128점이다. 점수가 높을수록 부정적인 사회적 사건에 대한 파국적 결과를 더 강하게 믿는다는 것을 의미한다. 본 연구에서는 아동의 연 령과 문화적 특성을 고려하여 사장은 선생님으로, 댄스수업은 방과 후 배드민턴 수업 등으로 수정하여 사용하였다.

검증을 위해 아동 . 청소년학 교수 1 인, 박사 3 인에게 내용 타당도 검증을 받았다. 본 연구에서의 Cronbach's $\alpha$ 는 타인에 의한 부정적 평가 .95, 부정적 자기평가 .95, 부정적인 장기적 결과 .95, 전체 Cronbach's $\alpha$ 는 .98로 나타났다.

불안통제신념 불안통제신념을 측정하기 위하여 개정된 한국판 불안통제 질문지(Korean version of Anxiety Control Questionnaire Revised [KACQ-R])를 사용하였다. 이는 Rapee, Craske, Brown과 Barlow (1996)가 개발한 불안통제 질문지를 Brown, White, Forsyth와 Barlow (2004)가 보완한 방식에 따라 $\mathrm{Oh}$ 와 $\mathrm{Oh}$ (2009)가 번안한 것이다. 총 19문항으로 구성되어 있 으며 하위요인으로는 감정통제 10 문항(예: "나는 보통 원할 때 면 언제나 긴장을 풀 수 있다.”), 위협통제 5문항(예: “뮌가에 크게 놀라면, 내가 할 수 있는 게 아무 것도 없다.”), 통제무력 감 4문항(예: "나는 성공적으로 해결할 수 없기에 아예 갈등 그 자체를 피해버린다.”)이 있다. 6점 척도로 평정하였으며 9개 문항에 대해서는 역채점되었다. 총점의 범위는 0-95점이며 점 수가 높을수록 불안통제감이 높음을 의미한다. 본 연구에서의 Cronbach's $\alpha$ 는 감정통제 .84, 위협통제 .78, 통제무력감 .65, 전 체 Cronbach's $\alpha$ 는 .76로 나타났다.

\section{연구절차}

본 연구는 2018년 9월에 기관생명윤리위원회(Institutional Review Board [IRB])의 심의를 받아 연구를 진행하였으며 연구
절차는 다음과 같다. 먼저, 서울 및 수도권의 초등학교 다섯 곳 에 방문하여 연구 진행방식에 대해 설명한 뒤 동의서과 설문 지를 간식과 함께 배포하였다. 연구 참여자들은 가정에서 설 문에 응답한 뒤 봉투에 넣어 담임 선생님에게 제출하였고 아 동과 부모 모두 설문을 한 경우 모바일 상품권을 주었다.

\section{자료분석}

본 연구는 부모 우울, 과보호 양육행동, 아동의 인지적 왜곡이 아동의 불안에 미치는 직접, 간접 효과를 분석하기 위해 SPSS 21.0 (IBM Co., Armonk, NY)과 AMOS 18.0 (IBM Co., Armonk, $\mathrm{NY})$ 프로그램을 사용하였다. 도구의 Cronbach's $\alpha$ 를 산출하였 으며 기술통계치 및 상관분석결과를 제시하였다. 확인적 요인 분석을 통해 측정모형의 타당성을 검증한 후 구조방정식 모형 검증을 실시하였다. 검증모형의 적합도를 평가하기 위해 $\chi^{2}$, RMSEA, NFI, TLI, IFI, CFI를 확인하였으며 결측치 처리를 위 해 완전정보 최대우도법(full-information maximum likelihood) 을 사용하였다. 간접효과의 검증을 위하여 bootstrapping 절차 를 사용하여 .05에서 통계적 유의성을 확인하였다.

\section{Results}

\section{주요 변인들의 기술통계 및 상관분석}

측정변인의 기술통계치는 Table 2 와 같다. 구조방정식 모형의 13 개의 지표변수들에 대한 다변인 정규분포성을 검증한 결 과, 단변인의 왜도 절대값은 2 미만, 첨도는 4 미만으로 나타나 정규성 조건을 충족하는 것으로 나타났다. 아동의 불안과 인 지적 왜곡의 성차를 분석한 결과 성에 따른 유의한 차이가 없 는 것으로 나타나 성별의 차이를 두지 않고 분석을 진행하였 다. Table 3에 나타난 잠재변인들 간 상관 결과, 아동의 불안은 인지적 왜곡, 아버지의 불안과 과보호, 어머니의 불안과 과보 호 모두와 정적 상관이 있는 것으로 나타났다 $(p<.01)$.

\section{측정모형 검증}

아버지와 어머니 두 개의 측정모형에 대한 부합도를 검증한 결과는 Table 4에 제시되었다. 표와 같이 모든 지수가 부합도 기준에 양호하게 부합되는 것으로 나타났다. 또한 Table 5에 제시한 바와 같이 각각의 잠재변인들이 구성하는 지표변수의 
Table 2

Descriptive Statistics of Variables

\begin{tabular}{|c|c|c|c|c|c|c|c|}
\hline \multicolumn{3}{|c|}{ Variables } & Ranges & $M$ & $S D$ & Skewness & Kurtosis \\
\hline \multicolumn{8}{|l|}{ Child } \\
\hline Anxiety & & Trait anxiety & $20-60$ & 29.90 & 8.92 & .06 & -.79 \\
\hline \multirow[t]{5}{*}{ Cognitive distortion } & Interpretation bias & Affect control & $0-128$ & 20.78 & 9.23 & .18 & -.47 \\
\hline & & Threat control & $0-128$ & 11.98 & 11.35 & 1.51 & 1.36 \\
\hline & Anxiety control beliefs & Other's evaluation & $0-50$ & 34.42 & 27.74 & .75 & -.22 \\
\hline & & Self-evaluation & $0-25$ & 30.85 & 24.03 & .96 & -.13 \\
\hline & & Long-term effect & $0-20$ & 24.83 & 21.26 & 1.16 & .29 \\
\hline \multicolumn{8}{|l|}{ Father } \\
\hline & & Control & $5-20$ & 9.14 & 2.52 & .62 & .13 \\
\hline & & Anxiety & $5-20$ & 8.52 & 2.70 & .76 & 1.01 \\
\hline \multicolumn{8}{|l|}{ Mother } \\
\hline \multirow[t]{2}{*}{ Anxiety } & & Trait anxiety & $20-80$ & 36.61 & 8.90 & .84 & 1.26 \\
\hline & & State anxiety & $20-80$ & 36.45 & 9.48 & .55 & .15 \\
\hline \multirow[t]{3}{*}{ Overprotection } & & Expectation & $5-20$ & 10.21 & 4.53 & .60 & -.02 \\
\hline & & Control & $5-20$ & 10.83 & 4.26 & .58 & -.07 \\
\hline & & Anxiety & $5-20$ & 11.19 & 4.08 & .52 & -.17 \\
\hline
\end{tabular}

Table 3

Correlations Among Variables

\begin{tabular}{|c|c|c|c|c|c|c|c|c|}
\hline & & & 1 & 2 & 3 & 4 & 5 & 6 \\
\hline 1 & Child & Anxiety & - & & & & & \\
\hline 2 & & Cognitive distortion & $.74^{* *}$ & - & & & & \\
\hline 3 & Father & Anxiety & $.45^{* *}$ & $.33^{* *}$ & - & & & \\
\hline 4 & & Overprotection & $.29^{* *}$ & $.18^{* *}$ & $.07^{*}$ & 一 & & \\
\hline 5 & Mother & Anxiety & $.30^{* *}$ & $.24^{* *}$ & $.35^{*}$ & $.13^{* *}$ & - & \\
\hline 6 & & Overprotection & $.25^{* *}$ & $.18^{* *}$ & $.07^{*}$ & $.71^{* *}$ & $.14^{*}$ & - \\
\hline
\end{tabular}

Note. $N=414$.

${ }^{*} p<.05 .{ }^{* *} p<.01$.

Table 4

Model Fit Indices for Measurement Models

\begin{tabular}{ccccccc}
\hline \multicolumn{1}{c}{ Models } & $\chi^{2}$ & RMSEA & NFI & TLI & IFI & CFI \\
\hline Father-Child & 1021.46 & .041 & .894 & .862 & .913 & .920 \\
Mother-Child & 1434.10 & .050 & .863 & .856 & .889 & .897 \\
\hline
\end{tabular}


Table 5

Estimation of Parameter in Measurement Models

\begin{tabular}{|c|c|c|c|c|c|c|c|c|}
\hline Model & & Latent & Indicators & $B$ & $\beta$ & $S E$ & C.R. & SMC \\
\hline \multirow{13}{*}{$\begin{array}{l}\text { Father-child } \\
\text { model }\end{array}$} & \multirow[t]{2}{*}{ Child's anxiety } & & Trait anxiety & 1.00 & .88 & & & .78 \\
\hline & & & State anxiety & .96 & .77 & .05 & $19.25^{* * *}$ & .60 \\
\hline & \multirow[t]{6}{*}{ Cog. distortion } & Interpretation bias & Affect control & 1.00 & .81 & & & .65 \\
\hline & & & Threat control & 1.32 & .90 & .06 & $22.57^{* * *}$ & .80 \\
\hline & & & Helplessness & .61 & .89 & .03 & $22.14^{* * *}$ & .78 \\
\hline & & Anxiety control beliefs & Other's evaluation & 3.25 & .92 & .14 & $23.53^{* * *}$ & .85 \\
\hline & & & Self-evaluation & 3.80 & .94 & .16 & $24.45^{* * *}$ & .89 \\
\hline & & & Negative long-term & 3.17 & .96 & .13 & $25.24^{* * *}$ & .92 \\
\hline & \multirow{2}{*}{\multicolumn{2}{|c|}{ Father's anxiety }} & Trait anxiety & 1.00 & .92 & & & .84 \\
\hline & & & State anxiety & 1.26 & .96 & .05 & $28.11^{* * *}$ & .93 \\
\hline & \multirow{3}{*}{\multicolumn{2}{|c|}{ Overprotection }} & Expectation & .85 & .67 & .07 & $12.67^{* * *}$ & .45 \\
\hline & & & Control & .57 & .53 & .06 & $10.04^{* * *}$ & .41 \\
\hline & & & Anxiety & 1.00 & .86 & & & .75 \\
\hline \multirow{13}{*}{$\begin{array}{l}\text { Mother-child } \\
\text { model }\end{array}$} & \multirow{2}{*}{\multicolumn{2}{|c|}{ Child anxiety }} & Trait anxiety & 1.00 & .89 & & & .79 \\
\hline & & & State anxiety & .95 & .77 & .05 & $19.06^{* * *}$ & .60 \\
\hline & \multirow[t]{6}{*}{ Cognitive } & Interpretation bias & Affect control & 1.00 & .81 & & & .65 \\
\hline & & & Threat control & 1.35 & .92 & .06 & $23.69^{* * *}$ & .84 \\
\hline & & & Helplessness & .62 & .90 & .03 & $22.93^{* * *}$ & .81 \\
\hline & & Anxiety control beliefs & Other's evaluation & 3.18 & .90 & .14 & $23.13^{* * *}$ & .82 \\
\hline & & & Self-evaluation & 3.75 & .93 & .15 & $24.28^{* * *}$ & .87 \\
\hline & & & Negative long-term & 3.13 & .95 & .12 & $25.24^{* * *}$ & .91 \\
\hline & \multirow{2}{*}{\multicolumn{2}{|c|}{ Mother's anxiety }} & Trait anxiety & 1.00 & .90 & & & .87 \\
\hline & & & State anxiety & 1.10 & .93 & .05 & $22.67^{* * *}$ & .81 \\
\hline & \multirow{3}{*}{\multicolumn{2}{|c|}{ Overprotection }} & Expectation & .51 & .79 & .02 & $25.03^{* * *}$ & .62 \\
\hline & & & Control & .47 & .77 & .02 & $24.01^{* * *}$ & .60 \\
\hline & & & Anxiety & 1.00 & .95 & & & .98 \\
\hline
\end{tabular}

${ }^{* * *} p<.001$

요인 부하량은 .77 .95 사이로 모두 $p<.001$ 수준에서 통계적 으로 유의한 것으로 나타났다. 잠재변인에 대한 지표변수의 요인 부하량은 평균이 최소한 .60 이상이어야 측정하고자 하 는 잠재변인을 잘 설명할 수 있다는 점에서 Moon (2009)이 제 시한 대로 본 연구의 측정모델들은 수렴타당도를 만족하는 것 으로 볼 수 있다.

\section{구조방정식모형 검증}

다음으로 잠재변인들 간 인과적 관계를 설정한 구조방정식모
형의 부합도 및 모수치를 추정하였다.

$$
\text { 아버지 모형 }
$$

구조방정식모형 분석 결과, Table 6과 같이 아버지 불안에서 과보호로 가는 경로를 제외하고는 모든 경로가 유의한 것으로 나타났다. 각각의 경로에 대해 구체적으로 살펴보면 다음과 같다. 첫째, 아동의 인지적 왜곡에서 불안으로의 경로는 정적 으로 유의하였다. 이는 아동이 인지적 왜곡을 할수록 불안 수 준도 높아짐을 의미한다. 다음으로 아버지의 과보호와 불안에 
Table 6

Standardized Parameter Estimates for the Father-Child Model

\begin{tabular}{|c|c|c|c|c|}
\hline \multicolumn{3}{|c|}{ Path } & \multirow{2}{*}{$\begin{array}{r}\text { Estimate } \\
.704^{* * *}\end{array}$} & \multirow{2}{*}{$\begin{array}{l}S E \\
.045\end{array}$} \\
\hline Cognitive distortion & $\rightarrow$ & Child's anxiety & & \\
\hline Overprotection & $\rightarrow$ & Child's anxiety & $.196^{* * *}$ & .049 \\
\hline Father's anxiety & $\rightarrow$ & Child's anxiety & $.260^{* * *}$ & .049 \\
\hline Overprotection & $\rightarrow$ & Cognitive distortion & $.186^{* *}$ & .073 \\
\hline Father's anxiety & $\rightarrow$ & Cognitive distortion & $.320^{* * *}$ & .058 \\
\hline Father's anxiety & $\rightarrow$ & Overprotection & .052 & .080 \\
\hline
\end{tabular}

${ }^{* *} p<.01 .{ }^{* * *} p<.001$.

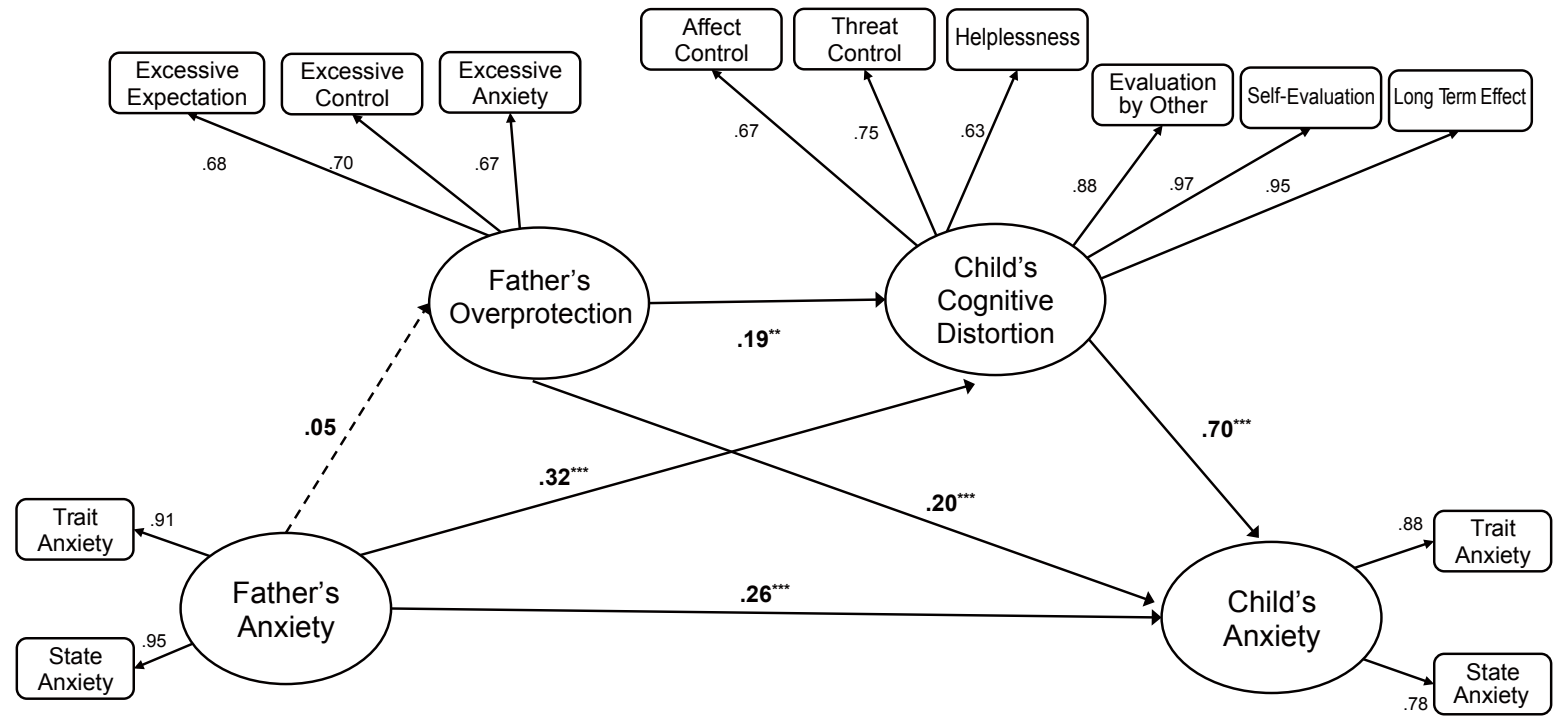

Figure 2. Path coefficients in the father-child model.

${ }^{* *} p<.01 .{ }^{* * *} p<.001$.

Table 7

Standardized Parameter Estimates for the Mother-Child Model

\begin{tabular}{|c|c|c|c|c|}
\hline \multicolumn{3}{|c|}{ Path } & \multirow{2}{*}{$\begin{array}{r}\text { Estimate } \\
.761^{* * *}\end{array}$} & \multirow{2}{*}{$\begin{array}{c}S E \\
.043\end{array}$} \\
\hline Cognitive distortion & $\rightarrow$ & Child's anxiety & & \\
\hline Overprotection & $\rightarrow$ & Child's anxiety & $.147^{* *}$ & .057 \\
\hline Mother's anxiety & $\rightarrow$ & Child's anxiety & $.117^{*}$ & .053 \\
\hline Overprotection & $\rightarrow$ & Cognitive distortion & $.169^{*}$ & .068 \\
\hline Mother's anxiety & $\rightarrow$ & Cognitive distortion & $.222^{* *}$ & .065 \\
\hline Mother's anxiety & $\rightarrow$ & Overprotection & $.191^{*}$ & .084 \\
\hline
\end{tabular}

${ }^{*} p<.05 .{ }^{* *} p<.01 .{ }^{* * *} p<.001$.

서 아동의 불안으로의 경로는 정적으로 유의하였다. 이는 아 버지가 과보호 양육을 하고 불안이 높을수록 아동의 불안이 높아짐을 의미한다. 또한 아버지의 과보호와 불안에서 아동의 인지적 왜곡으로의 경로가 정적으로 유의하였다. 이는 아버지 가 과보호와 불안이 아동의 인지적 왜곡에 영향을 미치는 것 을 보여준다. 그러나 아버지의 불안에서 과보호 양육으로의
경로는 유의하지 않았다(Figure 2).

\section{어머니 모형}

구조방정식모형 분석 결과가 Table 7에 제시되어 있다. 어머 니-아동 모형에서는 모든 경로가 유의한 것으로 나타났다. 우 


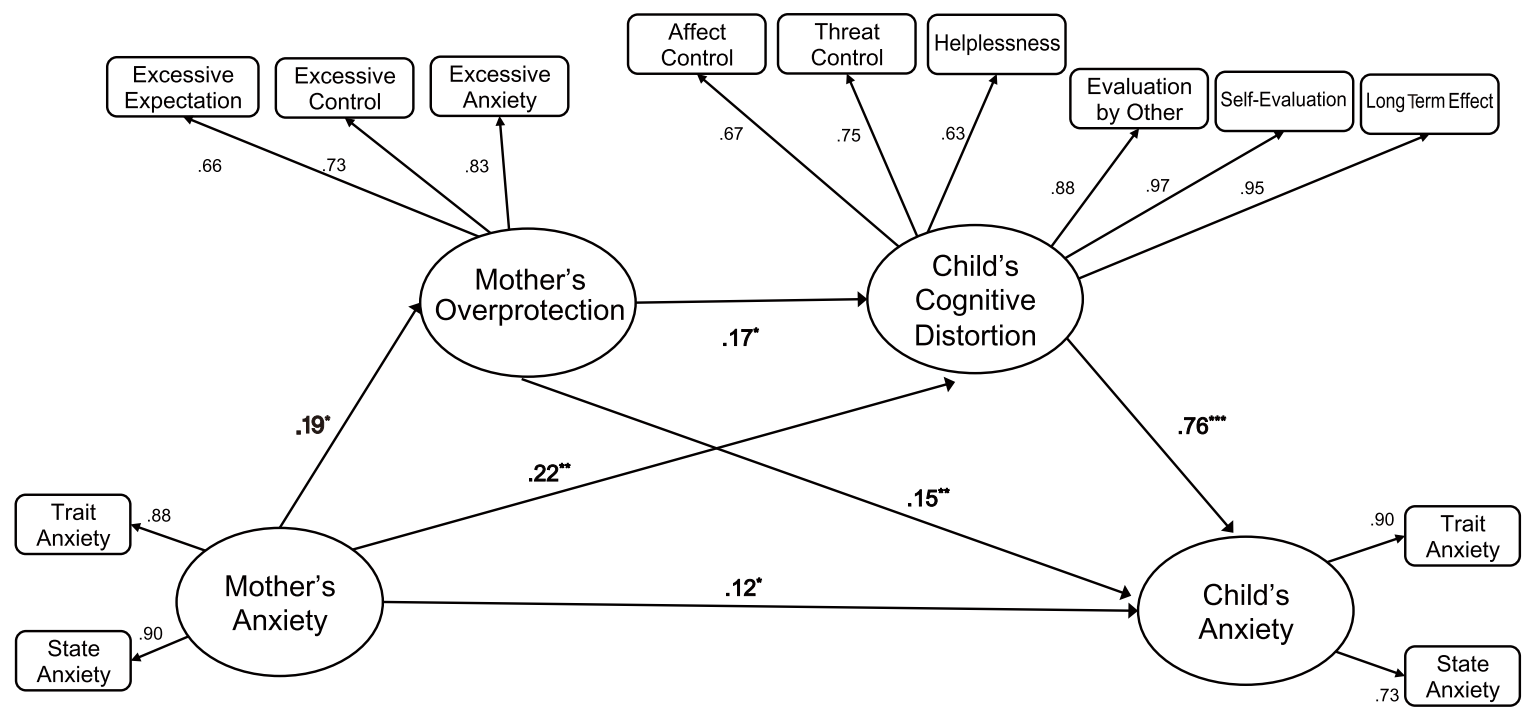

Figure 3. Path coefficients in the mother-child model.

${ }^{*} p<.05 .{ }^{* *} p<.01 .{ }^{* * *} p<.001$.

Table 8

Direct and Indirect Effects for the Father-Child Model

\begin{tabular}{llllcc}
\hline & & & \multicolumn{3}{c}{ Standardized } \\
\cline { 3 - 5 } & \multicolumn{2}{c}{ Parameter } & Total & Direct & Indirect \\
\hline Cognitive distortion & $\rightarrow$ & Child's anxiety & $.704^{* * *}$ & $.704^{* * *}$ & - \\
Overprotection & $\rightarrow$ & Child's anxiety & $.327^{* * *}$ & $.196^{* * *}$ & $.131^{*}$ \\
Father's anxiety & $\rightarrow$ & Child's anxiety & $.503^{* * *}$ & $.260^{* * *}$ & $.243^{* * *}$ \\
Overprotection & $\rightarrow$ & Cognitive distortion & $.186^{*}$ & $.186^{*}$ & - \\
Father's anxiety & $\rightarrow$ & Cognitive distortion & $.330^{* * *}$ & $.320^{* * *}$ & .010 \\
Father's anxiety & $\rightarrow$ & Overprotection & .052 & .052 & - \\
\hline
\end{tabular}

${ }^{*} p<.05 .{ }^{* * *} p<.001$.

Table 9

Direct and Indirect Effects for the Mother-Child Model

\begin{tabular}{lllllc}
\hline & & & \multicolumn{3}{c}{ Standardized } \\
\cline { 3 - 5 } & \multicolumn{2}{c}{ Parameter } & Total & Direct & Indirect \\
\hline Cognitive distortion & $\rightarrow$ & Child's anxiety & $.761^{* * *}$ & $.761^{* * *}$ & - \\
Overprotection & $\rightarrow$ & Child's anxiety & $.276^{* * *}$ & $.147^{* *}$ & $.129^{*}$ \\
Mother's anxiety & $\rightarrow$ & Child's anxiety & $.339^{* * *}$ & $.117^{*}$ & $.222^{* * *}$ \\
Overprotection & $\rightarrow$ & Cognitive distortion & $.169^{*}$ & $.169^{*}$ & - \\
Mother's anxiety & $\rightarrow$ & Cognitive distortion & $.255^{* * *}$ & $.222^{* *}$ & $.032^{*}$ \\
Mother's anxiety & $\rightarrow$ & Overprotection & $.191^{*}$ & $.191^{*}$ & - \\
\hline
\end{tabular}

${ }^{*} p<.05 .{ }^{* *} p<.01 .{ }^{* * *} p<.001$. 
선, 아동의 인지적 왜곡과 불안으로의 경로가 유의하였다. 어 머니 과보호와 불안에서 아동 불안과 인지적 왜곡으로 가는 경로 모두 유의하였다. 즉, 과보호를 많이 하고 불안이 높은 어 머니의 자녀일수록 불안도 높고 인지적 왜곡이 심한 것을 보 여준다. 한편, 아버지와는 달리 어머니에서는 불안에서 과보 호 양육으로의 경로는 정적으로 유의하여 어머니 불안이 높을 수록 과보호 양육행동이 높음을 보여준다(Figure 3).

\section{매개효과 검증: 직접효과와 간접효과}

총효과, 직접효과, 간접효과의 검증결과는 다음과 같다.

\section{아버지 모형}

연구모형에 대한 검증결과는 Table 8 과 같다. 아버지의 불안과 과보호는 아동의 불안에 직접적인 영향을 미칠 뿐 아니라 아 동의 인지적 왜곡을 매개하여 아동의 불안에 간접적인 영향을 미치는 것으로 나타났다. 그러나 아버지의 과보호 양육의 간 접 효과는 유의하지 않았다.

\section{어머니 모형}

Table 9를 살펴보면, 어머니의 과보호 양육행동은 인지적 왜곡 을 거쳐 아동의 불안에 영향을 미치는 매개효과가 유의한 것으 로 나타났다. 또한 어머니의 불안은 아동의 인지적 왜곡에 직 접적인 영향을 미칠 뿐 아니라 과보호 양육을 매개로 아동의 불안에도 간접적인 영향을 미치는 것으로 나타났다. 마지막으 로, 어머니의 과보호 양육과 아동의 인지적 왜곡 모두 어머니 의 불안과 아동의 불안과의 관계를 매개하는 것으로 나타났다.

\section{Discussion}

본 연구에서는 중기 아동기인 초등학교 고학년 학생과 그 아 버지 어머니를 대상으로 부모의 불안, 과보호 양육, 아동의 인 지적 왜곡 및 아동의 불안간의 관계를 파악하고 과보호 양육 과 인지적 왜곡의 매개효과를 살펴, 불안의 세대 간 전이의 메 커니즘에 대해 알아보았다. 그 결과는 다음과 같이 논의된다.

첫째, 부모의 과보호 양육은 인지적 왜곡을 매개로 아동의 불안에 간접적인 영향을 미쳤다. 즉, 부모의 과보호는 스스로 해결할 수 있는 위험을 경계하고 왜곡되게 해석하여 위협에
대한 인지적 편견을 가지게 하고 이것이 결국 아동의 불안으 로 이어지게 한다(Vasey \& McLeod, 2001). 이러한 결과는 과 도한 부모의 통제나 보호를 받은 아동은 모호하거나 도전적 인 상황을 위협적으로 지각하고 자신의 통제 하에 있지 않다 고 느껴 불안 수준이 증가한다는 연구들과 일치한다(Chorpita \& Barlow, 1998; Hudson \& Rapee, 2004; Wood, 2006). 또한 부 모의 과보호적 돌봄은 아동이 정서적 안정을 얻지 못하고 부 정적 정서 상태에 빠지게 하며 외현화 문제행동보다 우울, 불 안, 위축과 같은 내면화 문제행동과 더 관련된다고 보고한 선 행연구들과도 부합한다(M. J. Chung \& Kim, 2004; Davies \& Cummings, 1994; McLeod, Weisz, \& Wood, 2007).

경제협력개발기구(OECD) 회원국 중 유일하게 초저출산 국가로 분류된 우리나라는 자녀의 위치가 가족 내에서 높아지 고 뚜렷한 대안 없이 자녀의 요구를 최대한 받아주는 과보호 양육방식이 민주적이고 수용적인 양육방식인 것처럼 왜곡되 어 확산되고 있는 경향이 있다(Ahn \& Mo, 2012). 이는 부모가 자녀에 대한 사랑과 관심의 표현으로 보이나 실제로는 건강한 자아를 발달시킬 기회를 잃게 할 수 있다. 특히 아동이 자신의 환경을 적극적으로 탐색하고 어려운 상황에 대처하는 기술을 습득하는 기회를 막아 위협에 대한 대처를 하지 못하게 막는 다. 따라서 부모는 자녀가 위험상황을 겪지 못하도록 과보호 하는 것이 아니라 스스로 이겨내고 다양한 경험과 실수를 통 해 배울 수 있도록 돕는 조력자의 역할을 해야 할 것이다.

또한 내면화 문제행동을 보이는 아동은 정상 아동에 비해 부모의 통제와 과보호를 높은 수준으로 지각하며 성인이 되어 서까지 독립을 하지 못하고 의존적인 상태로 남아있는 경우가 많다(Mills \& Rubin, 1990). 본 연구에서는 아동이 지각한 부모 의 과보호 양육행동을 측정하였는데 아동이 부모의 통제와 기 대가 높다고 지각할수록 불안수준이 높았으며 아버지와 어머 니가 아동 불안에 미치는 영향력이 유사한 것으로 나타났다. 이러한 결과는 더 이상 자녀양육이 어머니만의 역할이 아닌 부모의 공통적 역할이며 아동 불안이 역으로 부모의 과보호를 유발할 수 있음을 시사한다. 그러나 아버지와 어머니의 과보 호 양육행동 간 상관이 높은 것을 고려할 때, 실제 양육행동과 는 다를 수 있음을 유의해서 해석할 필요가 있을 것이다.

둘째, 아버지의 불안과 아동의 불안 간 관계에서 인지적 왜 곡의 간접효과는 유의하였으나 과보호 양육은 유의하지 않았 다. 그러나 어머니의 불안은 과보호 양육과 인지적 왜곡을 매개 로 아동의 불안에 간접적인 영향을 미쳤다. 즉, 불안한 아버지 는 자녀가 불안한 상황이나 어려움을 왜곡되게 해석하고 사건 에 직면했을 때 잘 대처하지 못할 것이라는 신념에 영향을 미쳐 
결국 불안으로 이어지게 한다. 반면 불안한 어머니는 자신의 불 안으로 인해 자녀를 과도하게 보호하거나 통제하여 아동의 위 협에 대한 경계 수준을 높이고 모호한 상황에서도 위험하다고 판단하게 만들어 불안을 높이게 된다. 결국 아동은 자신이 처한 위협적 상황을 다뤄 본 경험이 거의 없기 때문에 시간이 지남에 따라 사건을 왜곡되게 해석하는 방식과 불안을 통제할 수 없다 는 신념이 안정적으로 자리 잡게 된다(Kim \& Park, 2017).

어머니와 다르게 아버지의 불안이 과보호로 이어지지 않은 것은 흥미로운 결과로 두 가지 관점에서 해석해볼 수 있다. 먼 저, 학령 중기는 사회적 관계가 학령 초기보다 확장되고 개별 교과목이 늘어남에 따라 학습시간과 학업부담이 증가하는 시 기이다. 또한 방과 후 다양한 활동이나 프로그램에 참여하여 진로 적성을 개발한다. 이 과정에서 아버지에 비해 어머니가 자녀의 교육이나 학교생활에 대해 더 많은 관여를 하고 자녀 와 더 많은 시간을 보내면서 인지.행동 양식을 자녀에게 모델 링할 기회가 더 많다(Halberstadt, Cassidy, Stifter, Parke, \& Fox, 1995; Lamb, 2000). 또한 긍정 및 부정적 정서 표현과 상호작용 모두 아버지-자녀 상호작용에서보다 어머니-자녀 상호작용에 서 더 빈번하다(Russell \& Russell, 1987; Shin \& Ha, 2010). 아동 기 불안의 예측변인을 알아보고자 4-12세까지 8년에 걸친 종 단연구 결과, 어머니가 불안장애를 지니고 있거나 자녀에게 높은 수준의 과잉개입을 한 경우 불안 증상을 보였다(Hudson, Murayama, Meteyard, Morris, \& Dodd, 2019). 따라서 불안한 어 머니는 일상에서 자녀에게 불안한 인지양식과 행동을 보이고 이것이 자녀가 자신의 주변 환경이나 역경에 대해 생각하고 해석하는 방식에 영향을 주어 불안감을 높였을 것이다.

두 번째로 부모의 성에 따라 자녀와 관계를 맺는 방식이 다 른데 어머니는 자녀와의 관계에서 친밀감을 중시하는 반면 아 버지는 자율성 획득에 초점을 둔다. 선행연구들은 어머니보 다 아버지가 자녀에게 독립적인 태도를 길러주고 위험을 감 수하고 도전해볼 수 있도록 돕는 역할을 한다고 하였다(Bogels $\&$ Phares, 2008; Paquette, 2004). 따라서 아버지 자신이 불안하 다고 해서 자녀를 더 보호하거나 통제하는 행동으로 이어지지 않는다는 것을 유추해볼 수 있다. 그러나 불안한 어머니는 자 신의 불안감으로 인해 자녀와의 관계나 삶이 불안하게 느껴 져 자녀를 더 통제하고 보호하게 된다. 특히, 우리나라는 서구 문화권 부모보다 자녀교육에 대한 열의가 높고 학업성취에 대 한 기대나 부담이 크기 때문에 이것이 어머니의 불안을 가중 시켜 자녀와의 관계에 더 부정적인 영향을 미쳤을 수도 있다 (Huntsinger, Jose, Liaw, \& Ching, 1997).

본 연구결과는 세대 간 불안이 전이되고 유지되는 악순환
을 예방하기 위한 인지 치료적 개입에 시사점을 가진다. 먼저, 불안이 높은 아동을 대상으로 위협적이거나 모호한 상황을 객 관적으로 판단하고 대처할 수 있도록 부정적인 해석편향을 수 정하고 긍정적인 정보처리양식을 갖도록 돕는 치료 프로그램 이 필요하다. 또한 문제 상황이나 불안을 유발하는 상황을 자 신이 통제할 수 있다고 지각할 수 있도록 통제 가능성에 대한 인지적 편향을 다뤄주는 것이 필요하다.

본 연구에서 아버지의 불안이 과보호 양육으로 이어지진 않았으나 부모가 과보호 양육을 보이는 경우에는 인지적 왜곡 을 통해 자녀 불안으로 이어지는 경로가 검증되었다. 부모-자 녀 관계 프로그램을 통해 부모의 과보호는 자녀가 능력 있는 존재라는 사실을 간과하고 자녀들이 세상을 탐색하고 실수로 부터 배울 수 있는 기회를 박탈한다는 것을 알려주고, 자녀의 자율성과 독립심을 기를 수 있도록 환경적 개입을 함께 제공 하는 것이 효과적일 수 있다. 특히, 어머니가 불안한 경우, 부 정적 양육행동으로 이어지고 이것이 자녀의 인지처리과정 및 심리적 건강에 악영향을 미친다는 것을 알려주고 불안을 다뤄 줄 필요가 있다.

본 연구의 제한점은 다음과 같다. 첫째, 본 연구는 일반 아 동을 대상으로 하였기 때문에 연구 결과를 다른 연령 혹은 임 상 집단에 적용할 수 있는지는 신중히 검토되어야 할 것이다. 또한 방임이나 학대의 문제가 있는 가족에게도 다른 결과가 나타날 수 있으므로 추후 연구에서는 연구 대상을 다양화하여 다른 패턴이 나타나는지 확인할 필요가 있을 것이다. 둘째, 본 연구에서 사용된 과보호 양육행동 척도는 우리나라 문화적 특 성이 반영된 것으로 아동이 부모의 행동을 보고하게 하였으 나 과잉 개입과 과보호가 다소 보편화되어 있는 한국사회에서 부모의 과보호 양육이 반드시 부정적으로 지각되지 않았을 가 능성이 있다. 추후 연구에서는 부모와 아동의 응답을 모두 측 정하여 둘 간의 상관을 살펴볼 필요가 있을 것이다. 마지막으 로 본 연구에서는 불안통제감과 해석편향을 합쳐서 인지적 왜 곡의 매개효과를 검증하였다. 기존 연구에서는 인지적 왜곡을 불안통제감과 해석편향 두 가지 요인으로 구분하여 측정한 적 이 없으므로 이후 연구에서는 아동의 인지적 왜곡에 대하여 더 구체적으로 살펴볼 필요가 있을 것이다.

\section{Notes}

This article is a part of the first author's doctoral dissertation submitted in 2019. 


\section{Conflict of Interest}

No potential conflict of interest relevant to this article was reported.

\section{Ethics Statement}

All procedures of this research were reviewed by IRB (SKKU 201809-001).

\section{References}

\section{In English}

Albano, A. M., Chorpita, B. F., \& Barlow, D. H. (2003). Childhood anxiety disorders. In E. J. Mash \& R. A. Barkley (Eds.), Child psychopathology (2nd ed., pp. 279-329). New York: The Guilford Press.

Barlow, D. H. (2000). Unraveling the mysteries of anxiety and its disorders from the perspective of emotion theory. American Psychologist, 55(11), 1247-1263. doi:10.1037/0003-066X. 55.11.1247

Barlow, D. H. (2001). Anxiety and its disorders: The nature and treatment of anxiety and panic (2nd ed.). New York: The Guilford Press.

Beck, A. T., Emery, G., \& Greenberg, R. L. (1985). Anxiety disorders and phobias: A cognitive perspective. New York: Basic Books.

Becker, K. D., Ginsburg, G. S., Domingues, J., \& Tein, J.-Y. (2010). Maternal control behavior and locus of control: Examining mechanisms in the relation between maternal anxiety disorders and anxiety symptomatology in children. Journal of Abnormal Child Psychology, 38(4), 533-543. doi:10.1007/ s10802-010-9388-z

Beidel, D. C., \& Turner, S. M. (1997). At risk for anxiety: I. Psychopathology in the offspring of anxious parents. Journal of the American Academy of Child \& Adolescent Psychiatry, 36(7), 918-924. doi:10.1097/00004583199707000-00013

Biederman, J., Petty, C. R., Hirshfeld-Becker, D. R., Henin, A., Faraone, S. V., Fraire, M., . . Rosenbaum, J. F. (2007). Developmental trajectories of anxiety disorders in offspring at high risk for panic disorder and major depression. Psychiatry Research, 153(3), 245-252. doi:10.1016/ j.psychres.2007.02.016
Bögels, S., \& Phares, V. (2008). Fathers' role in the etiology, prevention and treatment of child anxiety: A review and new model. Clinical Psychology Review, 28(4), 539-558. doi:10.1016/j.cpr.2007.07.011

Chorpita, B. F., \& Barlow, D. H. (1998). The development of anxiety: The role of control in the early environment. Psychological Bulletin, 124(1), 3-21. doi:10.1037/00332909.124.1.3

Creswell, C., O’Connor, T. G., \& Brewin, C. R. (2006). A longitudinal investigation of maternal and child 'anxious cognitions'. Cognitive Therapy and Research, 30(2), 135147. doi:10.1007/s10608-006-9021-1

Creswell, C., Schniering, C. A., \& Rapee, R. M. (2005). Threat interpretation in anxious children and their mothers: Comparison with nonclinical children and the effects of treatment. Behaviour Research and Therapy, 43(10), 13751381. doi:10.1016/j.brat.2004.10.009

Davies, P. T., \& Cummings, E. M. (1994). Marital conflict and child adjustment: An emotional security hypothesis. Psychological Bulletin, 116(3), 387-411. doi:10.1037/00332909.116.3.387

Eysenck, M. W., \& Calvo, M. G. (1992). Anxiety and performance: The processing efficiency theory. Cognition and Emotion, 6(6), 409-434. doi:10.1080/02699939208409696

Gallagher, B., \& Cartwright-Hatton, S. (2008). The relationship between parenting factors and trait anxiety: Mediating role of cognitive errors and metacognition. Journal of Anxiety Disorders, 22(4), 722-733. doi:10.1016/j.janxdis.2007. 07.006

Gullone, E. (2000). The development of normal fear: A century of research. Clinical Psychology Review, 20(4), 429-451. doi:10.1016/S0272-7358(99)00034-3

Hadwin, J. A., Garner, M., \& Perez-Olivas, G. (2006). The development of information processing biases in childhood anxiety: A review and exploration of its origins in parenting. Clinical Psychology Review, 26(7), 876-894. doi:10.1016/ j.cpr.2005.09.004

Halberstadt, A. G., Cassidy, J., Stifter, C. A., Parke, R. D., \& Fox, N. A. (1995). Self-expressiveness within the family context: Psychometric support for a new measure. Psychological Assessment, 7(1), 93-103. doi:10.1037/1040-3590.7.1.93

Harter, S. (1988). Developmental processes in the construction of the self. In T. D. Yawkey \& J. E. Johnson (Eds.), Integrative processes and socialization: Early to middle childhood (pp. 4578). Hillsdale, NJ: Lawrence Erlbaum Associates.

Harvey, A. G., Watkins, E., Mansell, W., \& Shafran, R. (2004). Cognitive behavioural processes across psychological disorders: A transdiagnostic approach to research and treatment. New York: Oxford University Press.

Hettema, J. M., Neale, M. C., \& Kendler, K. S. (2001). A review 
and meta-analysis of the genetic epidemiology of anxiety disorders. American Journal of Psychiatry, 158(10), 15681578. doi:10.1176/appi.ajp.158.10.1568

Hudson, J. L., Murayama, K., Meteyard, L., Morris, T., \& Dodd, H. F. (2019). Early childhood predictors of anxiety in early adolescence. Journal of Abnormal Child Psychology, 47(7), 1121-1133. doi:10.1007/s10802-018-0495-6

Hudson, J. L., \& Rapee, R. M. (2001). Parent-child interactions and anxiety disorders: An observational study. Behaviour Research and Therapy, 39(12), 1411-1427. doi:10.1016/ S0005-7967(00)00107-8

Hudson, J. L., \& Rapee, R. M. (2004). From anxious temperament to disorder: An etiological model. In R. G. Heimberg, C. L. Turk, \& D. S. Mennin (Eds.), Generalized anxiety disorder: Advances in research and practice (pp. 51-74). New York: The Guilford Press.

Huntsinger, C. S., Jose, P. E., Liaw, F.-R., \& Ching, W.-D. (1997). Cultural differences in early mathematics learning: A comparison of Euro-American, Chinese-American, and Taiwan-Chinese families. International Journal of Behavioral Development, 21(2), 371-388. doi:10.1080/016502597384929

Kendall, P. C. (1985). Toward a cognitive-behavioral model of child psychopathology and a critique of related interventions. Journal of Abnormal Child Psychology, 13(3), 357-372. doi:10.1007/BF00912722

Lamb, M. E. (2000). The history of research on father involvement: An overview. Marriage \& Family Review, 29(2-3), 23-42. doi:10.1300/J002v29n02_03

McLeod, B. D., Weisz, J. R., \& Wood, J. J. (2007). Examining the association between parenting and childhood depression: A meta-analysis. Clinical Psychology Review, 27(8), 986-1003. doi:10.1016/j.cpr.2007.03.001

Mills, R. S. L., \& Rubin, K. H. (1990). Parental beliefs about problematic social behaviors in early childhood. Child Development, 61(1), 138-151. doi:10.2307/1131054

Muris, P., \& Field, A. P. (2008). Distorted cognition and pathological anxiety in children and adolescents. Cognition and Emotion, 22(3), 395-421. doi:10.1080/02699930701843450

Muris, P., Huijding, J., Mayer, B., \& Hameetman, M. (2008). A space odyssey: Experimental manipulation of threat perception and anxiety-related interpretation bias in children. Child Psychiatry and Human Development, 39, 469-480. doi:10.1007/s10578-008-0103-z

Muris, P., Meesters, C., Schouten, E., \& Hoge, E. (2004). Effects of perceived control on the relationship between perceived parental rearing behaviors and symptoms of anxiety and depression in nonclinical preadolescents. Journal of Youth and Adolescence, 33(1), 51-58. doi:10.1023/A:102733431 4021

Muris, P., Merckelbach, H., \& Damsma, E. (2000). Threat perception bias in nonreferred, socially anxious children. Journal of Clinical Child Psychology, 29(3), 348-359. doi:10.1207/S15374424JCCP2903_6

Muris, P., Schouten, E., Meesters, C., \& Gijsbers, H. (2003). Contingency-competence-control-related beliefs and symptoms of anxiety and depression in a young adolescent sample. Child Psychiatry and Human Development, 33(4), 325-339. doi:10.1023/A:1023040430308

Muris, P., Vermeer, E., \& Horselenberg, R. (2008). Cognitive development and the interpretation of anxiety-related physical symptoms in 4-13-year-old non-clinical children. Journal of Behavior Therapy and Experimental Psychiatry, 39(1), 73-86. doi:10.1016/j.jbtep.2006.10.014

Paquette, D. (2004). Theorizing the father-child relationship: Mechanisms and developmental outcomes. Human Development, 47(4), 193-219. doi:10.1159/000078723

Pereira, A. I., Barros, L., \& Mendonça, D. (2012a). Cognitive errors and anxiety in school aged children. Psicologia: Reflexão e Crítica, 25(4), 817-823. doi:10.1590/S010279722012000400022

Pereira, A. I., Barros, L., \& Mendonça, D. (2012b). Perceived control and anxiety in Portuguese children. The Spanish Journal of Psychology, 15(2), 631-637. doi:10.5209/rev_ SJOP.2012.v15.n2.38874

Pereira, A. I., Barros, L., Mendonça, D., \& Muris, P. (2014). The relationships among parental anxiety, parenting, and children's anxiety: The mediating effects of children's cognitive vulnerabilities. Journal of Child and Family Studies, 23(2), 399-409. doi:10.1007/s10826-013-9767-5

Rapee, R. M. (1997). Potential role of childrearing practices in the development of anxiety and depression. Clinical Psychology Review, 17(1), 47-67. doi:10.1016/S0272-7358(96)00040-2

Russell, G., \& Russell, A. (1987). Mother-child and father-child relationships in middle childhood. Child Development, 58(6), 1573-1585. doi:10.2307/1130696

Spielberger, C. D. (1989). State-Trait Anxiety Inventory: A comprehensive bibliography (2nd ed.). Palo Alto, CA: Consulting Psychologists Press.

Van der Bruggen, C. O., Stams, G. J. J. M., \& Bögels, S. M. (2008). Research review: The relation between child and parent anxiety and parental control: a meta-analytic review. Journal of Child Psychology and Psychiatry, 49(12), $1257-$ 1269. doi:10.1111/j.1469-7610.2008.01898.x

Vasey, M. W., \& MacLeod, C. (2001). Information-processing factors in childhood anxiety: A review and developmental perspective. In M. W. Vasey \& M. R. Dadds (Eds.), The developmental psychopathology of anxiety (pp. 253-277). New York: Oxford University Press. doi:10.1093/med:psy ch/9780195123630.003.0012

Vreeke, L. J., Muris, P., Mayer, B., Huijding, J., \& Rapee, R. M. 
(2013). Skittish, shielded, and scared: Relations among behavioral inhibition, overprotective parenting, and anxiety in native and non-native Dutch preschool children. Journal of Anxiety Disorders, 27(7), 703-710. doi:10.1016/ j.janxdis.2013.09.006

Weems, C. F., Silverman, W. K., Rapee, R. M., \& Pina, A. A. (2003). The role of control in childhood anxiety disorders. Cognitive Therapy and Research, 27(5), 557-568. doi:10. 1023/A: 1026307121386

Whaley, S. E., Pinto, A., \& Sigman, M. (1999). Characterizing interactions between anxious mothers and their children. Journal of Consulting and Clinical Psychology, 67(6), 826836. doi:10.1037/0022-006X.67.6.826

Wilson, J. K., \& Rapee, R. M. (2005). The interpretation of negative social events in social phobia with versus without comorbid mood disorder. Journal of Anxiety Disorders, 19(3), 245-274. doi:10.1016/j.janxdis.2004.03.003

Wood, J. J. (2006). Parental intrusiveness and children's separation anxiety in a clinical sample. Child Psychiatry and Human Development, 37(1), 73-87. doi:10.1007/s10578-0060021-x

Woodruff-Borden, J., Morrow, C., Bourland, S., \& Cambron, S. (2002). The behavior of anxious parents: Examining mechanisms of transmission of anxiety from parent to child. Journal of Clinical Child \& Adolescent Psychology, 31(3), 364-374. doi:10.1207/153744202760082621

\section{In Korean}

Ahn, H.-J., \& Mo, A.-R. (2012). A study on the relationship between the child's perceived mother's overprotection and the child's problematic behaviors by the child's enneagram personality type. Korean Journal of Family Welfare, 17(3), 125-148.

Choi, J.-S., \& Cho, S.-C. (1990). Assessment of anxiety in childrenReliability and validity of revised children's manifest anxiety scale-. Journal of the Korean Neuropsychiatric Association, 29(3), 691-702.

Chun, S. (2012). Mother's over-protectiveness and adolescent' anxiety-The effects of mediation on adolescent' autonomy. The Korean Journal of the Human Development, 19(4), 6179.

Chung, E.-Y., \& Chang, S. (2008). The development of an overprotection scale based on teenagers' perception of their mothers. The Korean Journal of Counseling and Psychotherapy,
20(2), 293-312.

Chung, M. J., \& Kim, M. J. (2004). Relationships between children's behavior problems and their perceptions of parental childrearing practices. Korean Journal of Child Studies, 25(5), 11-27.

Kim, S., \& Park, K.-H. (2017). The effects of behavioral inhibition and parenting behaviors on interpretation bias in social anxiety. Korean Journal of Clinical Psychology, 36(4), 617629.

Moon, S. (2009). Basic concepts and applications of structural equation modeling. Seoul: Hakjisa.

Oh, Y., \& Oh, K.-S. (2009). Confirmatory factor analysis of the revised Korean version of the anxiety control questionnaire: Testing configural and metric invariance across clinical and non-clinical samples. The Korean Journal of Clinical Psychology, 28(4), 995-1010.

Shin, M.-J., \& Ha, E. H. (2010). The mediating effects of negative cognition in the relationships between mothers' overprotective parenting attitudes and adolescents anxiety. The Korean Journal of Counseling and Psychotherapy, 22(2), 459-477.

Suh, K.-H., Sin, H.-J., \& Moon, J.-Y. (2010). Parent's over protection and social anxiety of their children. The Korean Journal of Stress Research, 18(1), 19-27.

Suk, M., \& Oh, I. (2014). Relations of perceived parental overprotection, negative automatic thought and anger among middle school students. Secondary Education Research, 62(3), 491-511.

Yoo, S. (2018). Gungnae cheongsonyeon jeongsinjilhwan 'simgak', jasal saenggak biyul $17.6 \%$ [국내 청소년 정신질환 '심각', 자살 생각 비율 17.6\%]. Kuki News. Retrieved August 20, 2019, from http://www.kukinews.com/news/article. html?no=577641

\section{ORCID}

$\begin{array}{ll}\text { Youngmi Kim } & \text { http://orcid.org/0000-0001-9394-1990 } \\ \text { Hana Song } & \text { http://orcid.org/0000-0002-7745-7303 }\end{array}$

Received August 31, 2019

Revision received September 25, 2019

Accepted October 1, 2019 